\section{Analysis of World Research on Grafting in Horticultural Plants}

Luis J. Belmonte-Ureña

Department of Economics and Business, University of Almeria, Carretera Sacramento s/n, 04120 Almeria, Spain; and CIAIMBITAL, Campus of International Agrifood Excellence, University of Almeria, Carretera Sacramento s/n, 04120 Almería, Spain

\section{Jose A. Garrido-Cardenas}

Department of Biology and Geology, University of Almeria, Carretera Sacramento s/n, 04120 Almeria, Spain; and CIAIMBITAL, Campus of International Agrifood Excellence, University of Almeria, Carretera Sacramento s/n, 04120 Almería, Spain

\section{Francisco Camacho-Ferre}

Department of Agronomy, University of Almeria, Carretera Sacramento $s / n$, 04120 Almeria, Spain; and CIAIMBITAL, Campus of International Agrifood Excellence, University of Almeria, Carretera Sacramento $s / n, 04120$ Almería, Spain

Additional index words. bibliometric analysis, horticulture, plants, scientific research, vegetable grafting

\begin{abstract}
The research on grafting in horticultural plants has increased in recent years due to the benefits of grafting on disease control, productivity, and fruit quality. This study analyzes the scientific production on grafting in horticultural plants, using bibliometric techniques with the objective of obtaining a vision of the characteristics of the work carried out in the world on this subject. The worldwide evolution of research in this field was analyzed from 1979 to 2018 using a bibliometric analysis of 1376 articles. The analysis provided evidence of scientific production of authors, institutions, and countries. The results showed a growing interest on grafting in horticultural plants, mainly in the past decade when $73 \%$ of the total analyzed articles were published. The most productive subject area was Agricultural and Biological. The most productive journal was Scientia Horticulturae, and the one that obtained highest number of citations was Plant Physiology. The most cited authors per article were Colla, Roupahel, and Cardarelli. The most prolific institution was Agricultural Research Organization of Israel. China, United States, and Spain were the countries that published the most articles. The countries with the highest percentage of international collaboration were Germany and United Kingdom.
\end{abstract}

Since 1000 BCE, the Chinese have been grafting woody plants. Aristotle (384-322 BCE) published works describing grafting practices in detail. For the Roman Empire, grafting was a regular technique, and the Romans used different grafting methods. In Renaissance Europe (1300-1500 BCE), there was a renewed interest in the grafting practices. In 16th-century England, grafting was a normal technique, and the matching of the cambium layers was of great importance, even though the function of this tissue was unknown (Hartmann and Kester, 1991).

The use of grafting in vegetables began in Japan in 1914, mainly to avoid fusariosis

Received for publication 12 Sept. 2019. Accepted for publication 21 Oct. 2019.

Published online 16 December 2019.

L.J.B.-U. is the corresponding author. E-mail: lbelmont@ual.es.

This is an open access article distributed under the $\mathrm{CC}$ BY-NC-ND license (https://creativecommons.org/ licenses/by-nc-nd/4.0/).
Traka-Mavrona et al., 2000), and 6) modify fruit quality characteristics (Choi, 1991; Lee, 1989; Ricárdez-Salinas et al., 2010).

The development of grafting techniques in vegetables in Europe has been intense since the mid-1980s, first in cucurbits and then in solanaceous plants. At the beginning of the 21 st century in many American countries, grafting was developed as a viable alternative to using methyl bromide as a soil disinfectant. In the development of the technique, the search of the suitable plant material to be used as a rootstock has required great effort. Throughout this process, different types of plant material were assessed. To summarize the findings, the characteristics that a plant material must have to be used as a rootstock in the commercial production of vegetables are the following: 1) It must present affinity and compatibility with the variety that is intended for growing. Not only is it necessary to unify materials, rootstock, and variety, grafted plants must also follow their usual growth cycle until the harvest of the fruits. 2) From a phytopathological perspective, the rootstock must have resistance or tolerance (or both) to soil pathogens. This can extend to diseases that affect the aerial system of the crop. 3) From a physiological perspective, rootstock must be resistant or tolerant (or both) to abiotic stress (stress due to low temperature, flooding, drought, salinity, etc.). 4) Vigor and strength are characteristics that guarantee the adaptation of grafted plants, increasing the efficiency in the use of production inputs such as fertilizers. 5) Easy handling must be also taken into account due to the organization, planning, and handling processes that imply the production of grafted plants in nurseries. Uniformity and homogeneity are required commercially, whether in response to field conditions or during germination, emergence, and cultivation under nursery conditions. 6) Finally, the fruits produced should not suffer from alterations that reduce quality, including both external and internal properties, such as taste.

From a physiological perspective, when a vegetal species is grafted, many aspects of growth and development undergo significant changes. The sequence of structural changes in herbaceous species grafting was reviewed by Andrews and Marquez (1993).

Compatibility is defined as the ability of two plants to satisfactorily join and develop as a compound plant. The difference between a compatible and incompatible grafting is not well defined because it includes not only species that have a close relation and join easily but also totally incompatible species. In general, compatibility is related with taxonomic affinity but with significant exceptions.

Tolerance to low temperatures by the rootstock is one of the most desirable characteristics for growing vegetables in greenhouses, with the aim of early production. There are significant differences in root growth with low soil temperatures $\left(<13{ }^{\circ} \mathrm{C}\right)$ when the Cucurbita. maxima $\times$ C. moschata or Lageneria siceraria interspecific hybrid is planted 
underneath watermelon compared with nongrafted watermelon plants (Marukawa, 1979; Okimura et al., 1986; Suzuki, 1972). Cucumber grafted onto Cucurbita ficifolia absorbs water and nutrients in winter and early spring more efficiently than nongrafted plants. Such absorption is related to an increase in breathing (Tachibana, 1982). Some authors agree that grafted plants absorb water and nutrients better than do nongrafted plants (Cohen et al., 2000; Robinson and Decker-Walters, 1997). The physiological response to stress due to flooding has been investigated by Liao and Lin (1996) in Momordica charantia plants grafted onto Luffa cilindrica. As a result of this work, they demonstrated that the photosynthesis activity, the stomatal conductance and transpiration are reduced to a lesser extent in grafted plants compared with non-grafted plants.

There is evidence of compound translocation from the rootstock to the variety. In tomato fruits, the presence of alkaloids coming from Datura stramonium can be detected when it is grafted on this species or the presence of nicotine when it is grafted on tobacco (Hartmann and Kester, 1991). The rootstock role as a source of supply of plant hormones to the crop has to be taken into account. Its influence has been demonstrated in some studies of physiology in aubergine on cytokinins (Kato and Lou, 1989). These authors stated that plants with vigorous root systems produced a higher amount of cytokinins; they also directly related the increase in yield caused by a vigorous root system with the concentration of cytokinins present in the xylem. The composition of cytokinins in the xylem fluid is variable depending on the species.

For all the reasons just described, grafted plants require different cultural practices than nongrafted plants, including the graft position with respect to the soil, planting density, pruning system, nutrition system, and even when harvest must be carried out. Inappropriate cultural practices in grafted plants during their life cycle sometimes cause the development of herbaceous grafting to fail, even when the union stage and the preparation of grafted plants to be planted in the field have been done successfully.

The fundamental objective of this work is to obtain an overview of scientific production in the area of grafting in horticultural plants. For this purpose, bibliometric techniques have been used to facilitate the analysis of articles published in this area from the $1970 \mathrm{~s}$ to the present day.

\section{Materials and Methods}

A bibliometric analysis based on statistical, mathematic, and mapping tools was carried out. This permits the identification, organization, and analysis of the main components within a specific research area, as well as the representation of available metadata in the different databases and the determination of trends within a specific research field (Aznar-Sánchez et al., 2018;
Cobo et al., 2011; Donohue, 1972). Because this methodology reflects the most relevant authors, countries, journals, and keywords across past years, it shows how interest in a topic has increased. It can also identify different connections within research-for example, through the use of co-authorship and co-quation analysis.

Following the instructions of Gavel and Iselid (2008) and Hossain et al. (2018), different databases of scientific works, which are related to our field of study, were consulted. Finally, the Scopus database was chosen. Scopus is considered the biggest repository of peer-reviewed literature and includes the most relevant publications of the subject field of study. Furthermore, it is the database that provides the most information on each author, institution, and country (Mongeon and Paul-Hus, 2016).

The searches of articles on grafting were performed in Feb. 2019. The terms "graft" or "grafting" were used as parameter for this search in Scopus, and combined with the main horticultural crops that have been grafted, that is: "watermelon," "melon," "pepper," and "aubergine." The search was carried out on the title, abstract, and keywords for a 40-year period of study, from 1979 to 2018 , in a similar manner to other bibliometric works (Aznar-Sánchez et al., 2018; Perea-Moreno et al., 2017). Thus, the search query was [TITLE-ABS-KEY (graft AND grafting)].

The final sample consisted of 1376 articles, which formed a data panel from 1979 to 2018 , with a wide range of analyzed variables, such as publication year, journal, subject area, author and coauthors of the work, institutions and affiliation country of authors, and the keywords that define the article.

The various indicators of scientific production used were the evolution in the number of articles published every year, the productivity of authors, countries and institutions, the count of works presented for each field, the count of the number of citations, the $\mathrm{H}$ index, and the Scimago Journal Rank (SJR) impact factor of the main works. Networking maps were made to analyze the collaboration between authors and countries and to search research trends based on the use of keywords. VOSviewer software tool was used to construct and analyze the networks (version 1.65; Leiden University, the Netherlands). VOSviewer is suitable for studies based on bibliometric analysis and is widely used to process and group terms (Leydesdorff et al., 2013; van Eck and Waltman, 2010).

For the analysis of the keywords, they were grouped according to an identical meaning but with a different orthography. On the other hands, keywords such as "article" or "review" that did not contribute to the analysis of the data were discarded.

\section{Results and Discussion}

Evolution of scientific production. The evolution of the main characteristics of arti- cles on grafting published from 1979 to 2018 is shown in Table 1 . As can be seen in all the analyzed variables, the interest in research on grafting grew throughout the period, especially over the past 20 years. Thus, within the period from 1979 to 1983 , only 14 articles were published on grafting; by contrast, in the past 5 years (2014-18), 572 articles were published, an increase of 40 times. The growth in the number of publications was especially noticeable in the past decade (2009-18), when 1004 were published, which amounts to $73 \%$ of the total number of articles published in the past 40 years. The highest number of publications, 131, took place in 2015, decreasing in 2018 to 104

The evolution in the number of articles and the percentage of variation for every 5year period throughout the study period is shown in Fig. 1. In addition to the significant increase in the number of articles published in the past 10 years, it is interesting to highlight the percentual growth produced during the 1994-98 and 2009-13 periods. In the first case, in 1996 and 1998, the publication of articles on grafting widely exceeded the annual average, and 1996 was the first year in which more than 10 articles on grafting were published. On the other hand, the increase in the number of publications, which is seen in percentage variation in 2009-13, is because 2013 was the first year in which 100 articles per year was exceeded; however, 5 years earlier, the annual average was at 12.4. The increase in publications may be due to the expansion of grafting technique in many developing countries because it is a viable choice for the elimination of biocides, such as methyl bromide, which has led to an increase in the consumption of grafted horticultural plants.

Parallel to the number of articles, the total number of authors also increased considerably in the past 10 years. In the 1979-2018 period, 5357 authors were registered, representing $73.9 \%$ of them. In the period 1979 83,31 authors were registered; by the 2014-18 period, there were 2284 authors. This increase is higher than the increase in the number of articles published because the average number of authors per article also increased. Thus, in 1979-83, the average number of authors per article was at 2.2; in

Table 1. Major characteristics of the articles of horticultural grafting from 1979 to 2018 .

\begin{tabular}{lrrrrrr}
\hline Yr & A & \multicolumn{1}{c}{ AU } & \multicolumn{1}{c}{ C } & \multicolumn{1}{c}{ TC } & TC/A & J \\
\hline $1979-83$ & 14 & 31 & 10 & 64 & 4.6 & 10 \\
$1984-88$ & 17 & 49 & 9 & 99 & 5.8 & 13 \\
$1989-93$ & 21 & 72 & 15 & 127 & 6.0 & 18 \\
$1994-98$ & 50 & 165 & 21 & 343 & 6.9 & 37 \\
$1999-2003$ & 84 & 310 & 26 & 1,143 & 13.6 & 60 \\
$2004-08$ & 186 & 772 & 38 & 3,037 & 16.3 & 116 \\
$2009-13$ & 432 & 1,674 & 61 & 10,086 & 23.3 & 160 \\
$2014-18$ & 572 & 2,284 & 68 & 15,425 & 27.0 & 160
\end{tabular}

\begin{tabular}{lllllll}
$2014-18$ & 572 & 2,284 & 68 & 15,425 & 27.0 & 160 \\
\hline $\mathrm{A}=$ annual number of
\end{tabular} authors; $\mathrm{C}=$ number of countries; $\mathrm{TC}=$ annual number of citations in total articles; $\mathrm{J}=$ number of journals. 


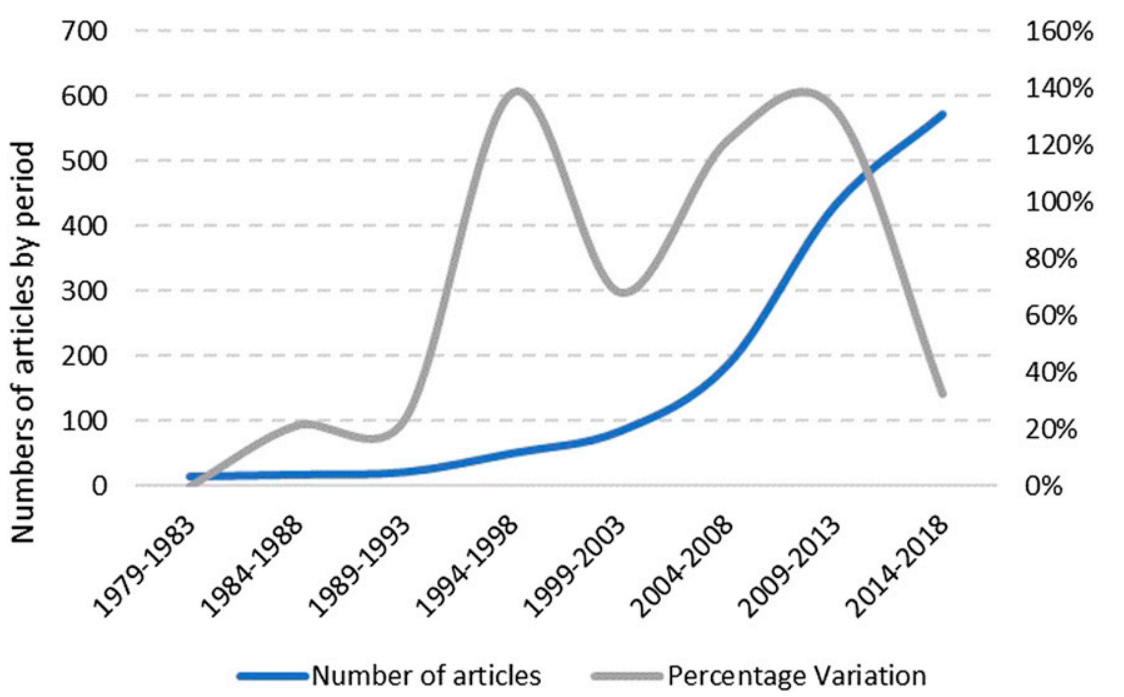

Fig. 1. Evolution in the number of articles and percentage variation between 5-year periods.

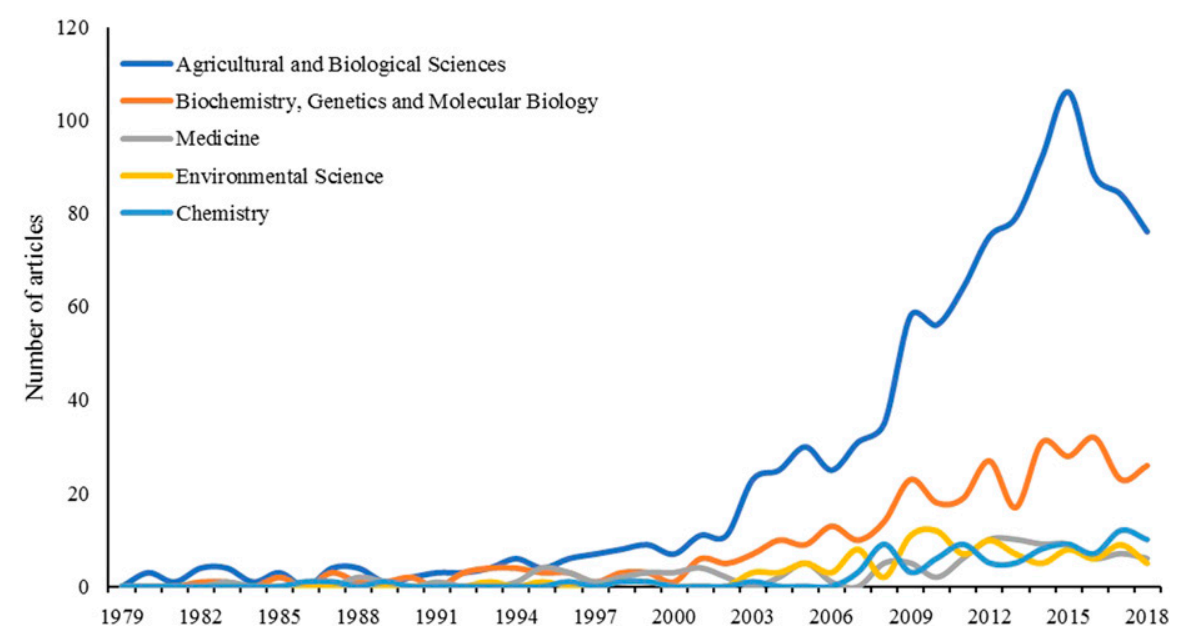

Fig. 2. Comparisons of the growth trends of subject areas in horticultural grafting research from 1979 to 2018.

the last period (2014-18), this reached four authors per article.

Likewise, the number of citations showed an exponential growth during the entire period, mainly in the last decade. Therefore, whereas in the first period, 1979-83, the total number of citations was 223 , in the last period, 2014-18, this amounted to 15,155 . The average number of citations per article grew from 15.9 to 26.4 .

Moreover, the number of citations has grown exponentially from 64 in the first period (1979-83) to 15,425 in the last 5 years analyzed (2014-18). The annual average number of citations per article increased from 4.6 , in the first 5-year subperiod to 26.9 in the last subperiod.

Finally, the number of journals that published articles on grafting increased from 10 in the period $1979-84$ to 160 in the period 2014-18. Likewise, the number of countries involved in the publication of articles on this topic increased from 10 in the first subperiod to 68 of the last 5 years analyzed. During the entire analyzed period, 1979-2018, the total number of countries that participated in the publication of articles on grafting amounted to 92 ; however, they do not all have the same significance, as we will analyze subsequently.

Distribution of scientific production by subject categories and journals. A priori, one can think that the term "graft" is only associated with the subject area of Agricultural and Biological Sciences. However, during the period analyzed, 1979-2018, there are several areas in which articles related with "graft" were found. Therefore, under Scopus classification, there are a total of 26 subject areas under which the 1376 articles analyzed are classified. It should be clear that an article can be simultaneously included in more than one category, depending on the author's interest and the editorial.

The evolution of the principal subject categories of the articles on grafting in the past 40 years is shown in Fig. 2. Agricultural and Biological Sciences is the dominant category throughout almost the entire period analyzed and has increased its advantage over the rest of categories since 2000 . Considering the period $1979-2018,51 \%$ of the articles on grafting have been published under this category. This is followed by Biochemistry, Genetics and Molecular Biology, Medicine, Environmental Science, and Chemistry, classified in order of importance. In total, the five most important categories (Fig. 2) represent $83 \%$ of the works published on grafting from 1979 to 2018 .

Although the category with the highest number of publications is included in the Agronomic Sciences, the categories related with Chemistry and Medicine account for more than $30 \%$ of the works. This fact can be related with the improvement of cultivars, the great expansion of grafting, the incorporation of grafted plant in different crop systems, and the increase in productivity of grafted plant, all of which make this technique a fundamental pillar to ensure success under suboptimal production conditions.

The characteristics of the most prolific journals for the number of articles on grafting are shown in Table 2. A high percentage of these 20 journals $(45 \%)$ are found in the first quartile of the SJR of 2017. Furthermore, over the years, grafting has been an interesting topic for more journals and authors, as demonstrated by the growth of the number of articles and the wide range of journals. Therefore, within the first analyzed decade, 1979-88, 31 articles on grafting were published in 20 journals, whereas in the last decade, 2009-18, 766 articles on this topic were distributed among 160 impact journals.

By nationality, the 20 most relevant journals for the number of articles published on grafting are from Europe or the United States, in addition to having a better position in the SJR ranking in 2017.

The journal that published most of the articles on grafting is Scientia Horticulturae, with 81 , which represents $6 \%$ of the total number of articles published between 1979 and 2018. This journal has also occupied first position in the ranking for more years, from 1999, and it generates a great interest within the scientific community, as demonstrated by the high volume of citations of its articles, 1445. Scientia Horticulturae also has the highest $\mathrm{H}$ index for articles published on grafting, 23, which is far behind the general $\mathrm{H}$ index of the journal for all the subject areas, which is placed at 84 .

Nevertheless, if we consider the number of citations, the American Journal of Plant Physiology had the best results in terms of the number of total citations and the average number of citations per article published, with 1613 citations and an average of 80.65 citations per article and the highest SJR impact factor: 3.690 (Q1). It is followed at a distance by Environmental and Experimental Botany, with 12 articles, 790 citations, and an average of 65.83 citations per article, with an $\mathrm{H}$ index of 12 for its articles on grafting and a high SJR impact factor SJR: 1.376 (Q1). 
Table 2. The most prolific journals in number of articles on horticultural grafting from 1979 to 2018.

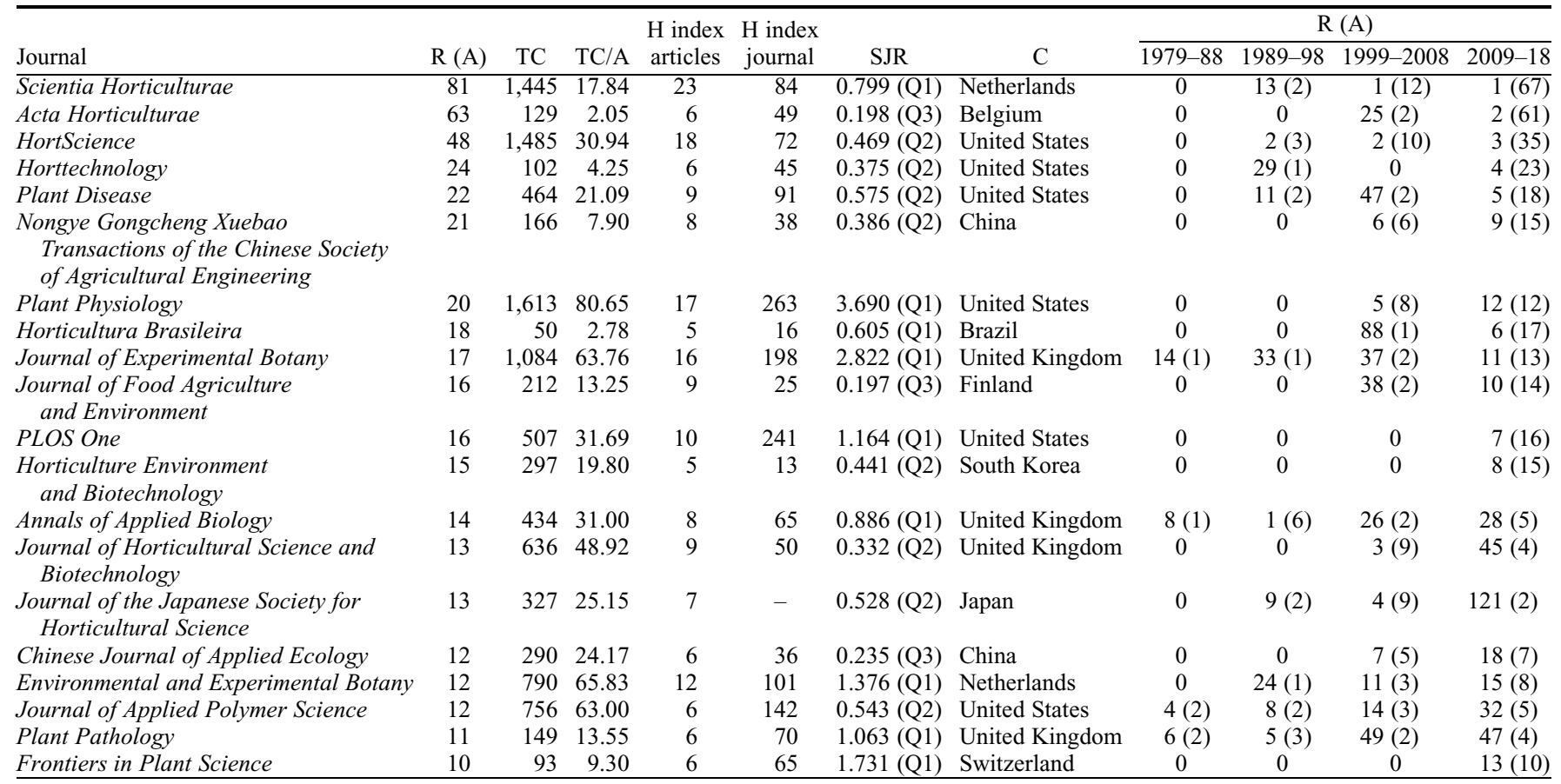

$\mathrm{A}=$ number of articles; $\mathrm{R}=$ rank position by number of articles; $\mathrm{TC}=$ number of citations for all articles; $\mathrm{TC} / \mathrm{A}=$ number of citations by article; $\mathrm{SJR}=\mathrm{Scimago}$ Journal Rank (quartile); C = country.

Table 3. The most prolific authors in number of articles on horticultural grafting from 1979 to 2018.

\begin{tabular}{|c|c|c|c|c|c|c|c|c|}
\hline Authors & A & $\mathrm{TC}$ & TC/A & Institution & $\mathrm{C}$ & First A & Last A & $\mathrm{H}$ index \\
\hline Colla, Giuseppe & 20 & 1,026 & 51.30 & Università degli Studi della Tuscia Viterbo & Italy & 2002 & 2017 & 17 \\
\hline Zhao, Xin & 17 & 192 & 11.29 & University of Florida & United States & 2009 & 2018 & 9 \\
\hline Cardarelli, Mariateresa & 15 & 827 & 55.13 & CREA-Centro di Ricerca per l'orticoltura, Pontecagnano & Italy & 2006 & 2016 & 14 \\
\hline Huang, Yuan & 13 & 84 & 6.46 & Huazhong Agricultural University & China & 2013 & 2018 & 5 \\
\hline Schwarz, Dietmar & 13 & 261 & 20.08 & Institut für Gemüse- und Zierpflanzenbau Großbeeren & Germany & 2009 & 2017 & 10 \\
\hline Edelstein, Menahem & 12 & 290 & 24.17 & Agricultural Research Organization of Israel & Israel & 1999 & 2017 & 9 \\
\hline
\end{tabular}

$\mathrm{A}=$ number of articles; $\mathrm{TC}=$ number of citations for all articles; $\mathrm{TC} / \mathrm{A}=$ number of citations by article; $\mathrm{C}=$ country.
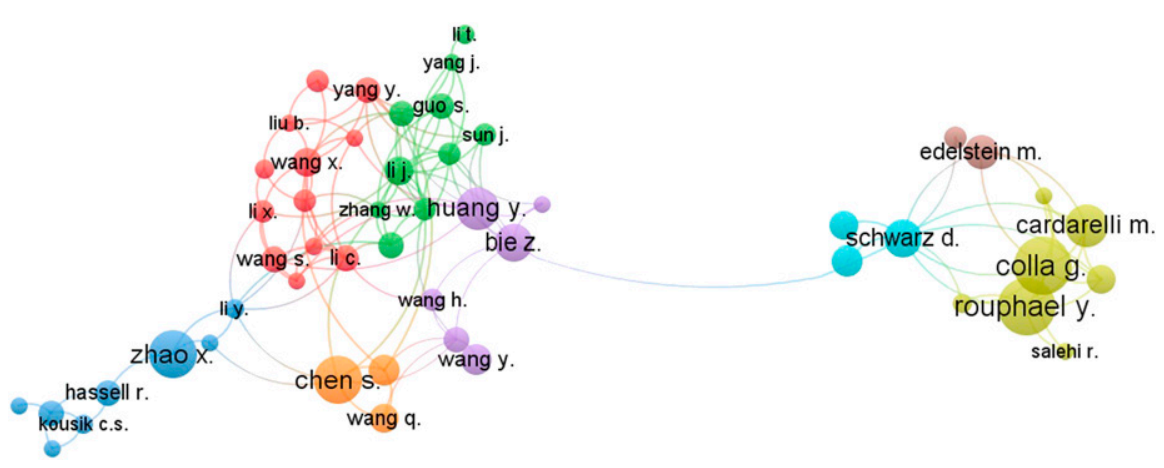

Fig. 3. Network of cooperation based on coauthorship between authors from 1979 to 2018.

Grafting issues have been dealt with in different ways by the main scientific journals worldwide. Some journals have published articles on grafting over the 40 years of the period of study, but others have successfully published on this topic only in the past 20 years. This is the case of the Belgian journal,
Acta Horticulturae, for which the first article on grafting dated from 2005 and from that date it published 63 articles on this subject area, which placed it in second position in the number of articles ranking. However, despite the publishing activity of this type of work, the $\mathrm{H}$ index of the articles on grafting that this journal, at 6 , is far behind the best registrations of the table.

Productivity of authors, institutions, and countries. The most prolific authors with the largest number of grafting articles published during the period 1979-2018 are shown in Table 3. The authors with the largest number of publications are Giuseppe Colla and Youssef Rouphael, both Italian, with 20 articles each. The author with the highest number of citations on grafting is Giuseppe Colla, with a total of 1026, who has the joint highest $\mathrm{H}$ index of 17 , together with his compatriot, Youssef Rouphael. It must be highlighted that the three Italian authors, Colla, Rouphael, and Cardarelli, are the authors with the highest average number of citations per article and the highest $\mathrm{H}$ index within this author ranking.

At the other end of the most important author ranking on grafting, we find two Chinese authors, Zhilong Bie and Yuan Huang, who have the lowest number of citations of their articles, which means a lower $\mathrm{H}$ index, 6 and 5 respectively. The 
Table 4. The most prolific institutions in number of articles on horticultural grafting from 1979 to 2018.

\begin{tabular}{|c|c|c|c|c|c|c|c|c|}
\hline Institution & $\mathrm{C}$ & A & $\mathrm{TC}$ & $\mathrm{TC} / \mathrm{A}$ & H index & IC $(\%)$ & TCIC & TCNIC \\
\hline Ministry of Education China & China & 31 & 338 & 10.90 & 12 & $25.8 \%$ & 19.25 & 8.00 \\
\hline CEBAS-CSIC, Centro de Edafología y Biología Aplicada del Segura & Spain & 28 & 1,307 & 46.68 & 16 & $35.7 \%$ & 57.50 & 40.67 \\
\hline University of Florida & United States & 28 & 680 & 24.29 & 13 & $17.9 \%$ & 31.40 & 22.74 \\
\hline USDA Agricultural Research Service, Washington, DC & United States & 27 & 1,008 & 37.33 & 12 & $25.9 \%$ & 72.43 & 25.05 \\
\hline Chinese Academy of Sciences & China & 27 & 797 & 29.52 & 13 & $29.6 \%$ & 38.13 & 25.89 \\
\hline
\end{tabular}

$\mathrm{C}=$ country; $\mathrm{A}=$ number of articles; $\mathrm{TC}=$ number of citations for all articles; TC/A = number of citations by article; $\mathrm{IC}=$ percentage of articles made with international collaboration; TCIC $=$ number of citations by article made with international collaboration; TCNIC $=$ number of citations by article made without international collaboration; USDA $=$ U.S. Department of Agriculture.

Table 5. The most prolific countries in number of articles on horticultural grafting from 1979 to 2018.

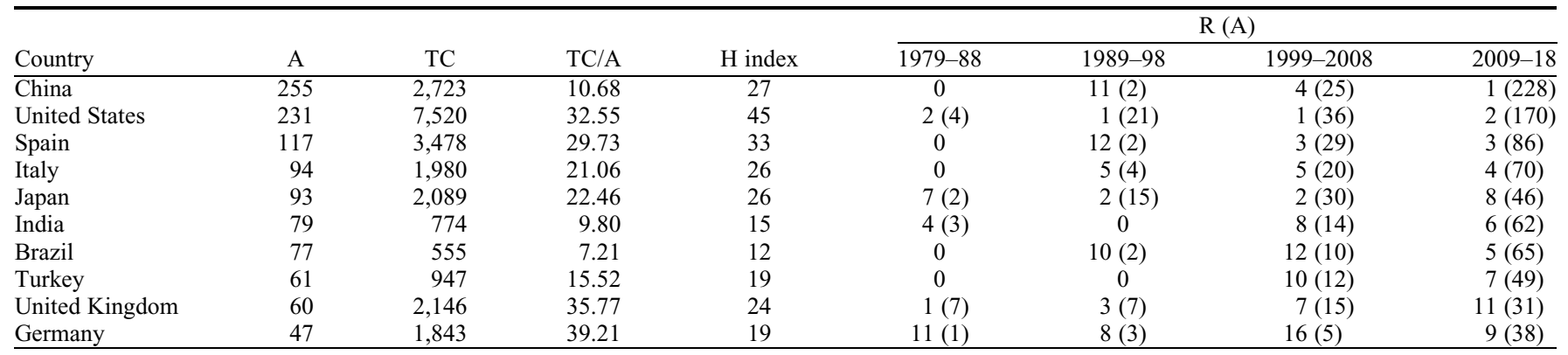

$\mathrm{A}=$ number of articles; $\mathrm{R}=$ rank position by number of articles; $\mathrm{TC}=$ number of citations for all articles; $\mathrm{TC} / \mathrm{A}=$ number of citations by article.

Table 6. The most prolific countries and international collaboration from 1979 to 2018.

\begin{tabular}{|c|c|c|c|c|c|}
\hline \multirow[b]{2}{*}{ Country } & \multirow[b]{2}{*}{$\mathrm{NC}$} & \multirow[b]{2}{*}{ Main collaborators } & \multirow[b]{2}{*}{ IC $(\%)$} & \multicolumn{2}{|c|}{$\mathrm{TC} / \mathrm{A}$} \\
\hline & & & & IC & NIC \\
\hline United States & 37 & China, South Korea, Israel, Spain, Japan & $33.8 \%$ & 44.42 & 26.50 \\
\hline Japan & 12 & China, United States, Bangladesh, Israel, Australia & $23.7 \%$ & 44.86 & 15.52 \\
\hline India & 9 & Italy, United States, Malaysia, Vietnam, Australia & $12.7 \%$ & 39.30 & 5.52 \\
\hline Brazil & 8 & Spain, Argentina, Belize, Chile, Germany & $14.3 \%$ & 12.55 & 6.32 \\
\hline Germany & 25 & Greece, Switzerland, Italy, Austria, China & $74.5 \%$ & 49.37 & 9.58 \\
\hline
\end{tabular}

$\mathrm{NC}=$ number of collaborators; $\mathrm{IC}=$ percentage of articles made with international collaboration; $\mathrm{TC} / \mathrm{A}=$ number of citations by article; IC $=$ international collaboration; NIC = no international collaboration.

low number of citations of Bie and Huang articles may be because they are recent contributors to the literature: Bie began to publish in 2011 and Huang in 2013; therefore, it is possible that they have not yet accumulated an important number of citations.

The Spanish author Juan Manuel García Ruiz, affiliated with the University of Granada, is the author with the oldest article, published in 1997, and he is also the fourth author, behind the three Italian authors, with the highest number of citations per article, 37.25 .

A network of cooperation based on coauthorship between the main authors is shown in Fig. 3. The different colors correspond to the clusters formed by the work groups in the production of articles, and the size of the circle varies with the number of articles published by each author. The green cluster is led by Giuseppe Colla, whose group in- cludes Rouphael and Cardarelli, among others. We find authors such as Hassell, Kousik, and $\mathrm{Li}$, among others, within the group of the American author Zhao (blue cluster). It is interesting to highlight that Italian, German, and Israeli authors collaborate closely (see cluster at the right of the figure), whereas Chinese and American authors, on the left side of the figure, collaborate closely with each other than with other nationalities. Finally, the two Spanish authors do not appear in Fig. 3, even though they are in the top 10 ranking of authors with most publications on grafting. This is due to the scarcity of international collaboration in their publications.

The 10 most prolific institutions on published articles related to grafting are shown in Table 4. The first institution is Agricultural Research Organization of Israel, with 34 articles and 987 citations. This institution has an $\mathrm{H}$ index of 17, the second most relevant position within the table and, in addition, more than a third of the articles, $35.3 \%$, were published with the collaboration of authors from other countries.

Spain, with three institutions, is the country with the highest presence within this ranking. Among them, the Universitat Politècnica of València is the institution with second highest number of articles on grafting, 33, which includes coauthorship by $30.3 \%$ of international authors. The other two Spanish institutions, CEBAS-CSIC and IVIA-Valencian Institute for Agricultural Research, showed a higher percentage of international coauthorship, with $35.7 \%$ and $40.0 \%$, respectively.

The institutions of Brazil and the University of Florida are those with the lowest percentage of articles with international coauthorship (lower than 20\%). The North American U.S. Department of Agriculture is the institution with the highest number of 


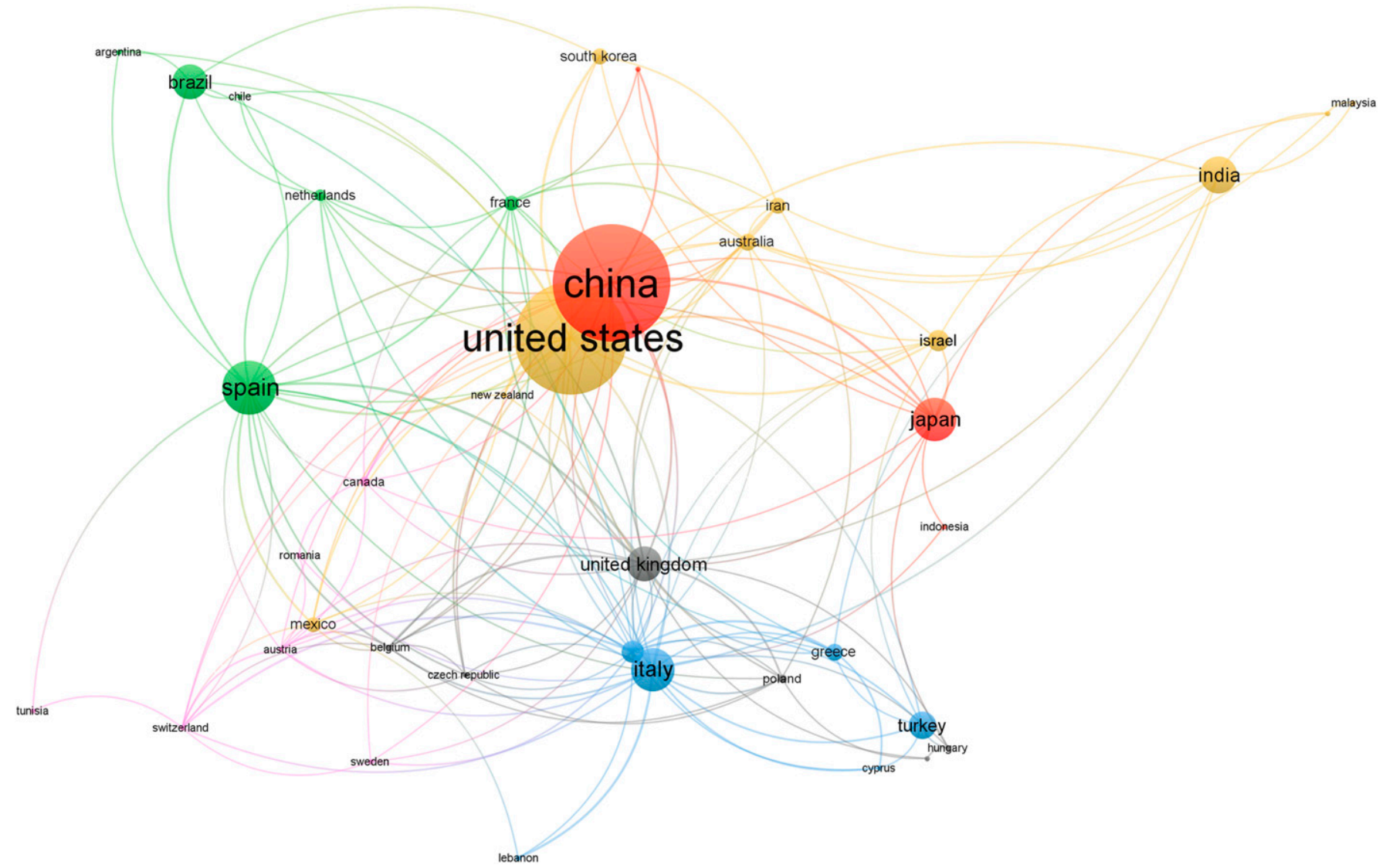

Fig. 4. Network of cooperation based on coauthorship between countries from 1979 to 2018.

Table 7. Main keywords in horticultural grafting research during 1979-2018.

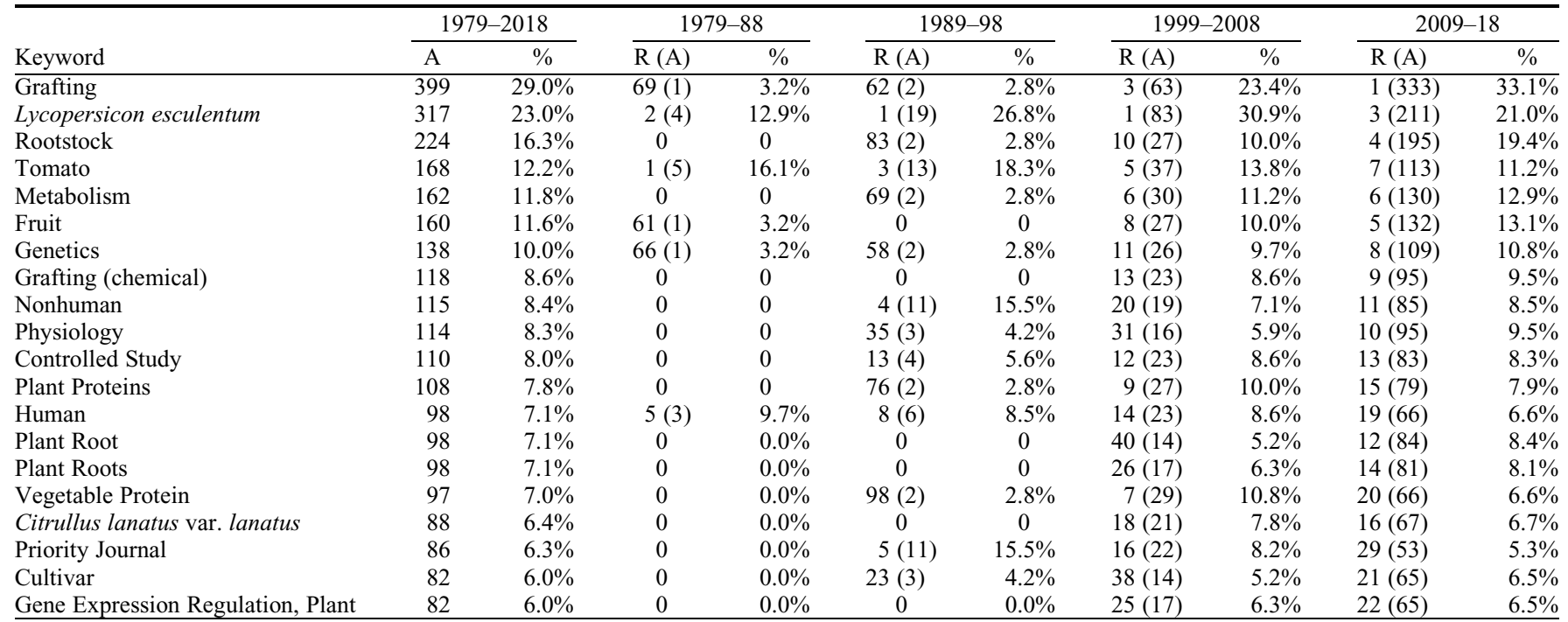

$\mathrm{A}=$ number of articles; $\mathrm{R}=$ rank position; $\%=$ percentage of articles in which it appears.

citations per article in the papers it published with international authors, 72.43. However, the most significant case with respect to the number of citations per article, whether national or international, is the Brazilian institution Universidade Estadual Paulista (UNESP), whose average number of citations exceeds five per article in the case of works without international coauthorship. It is possible that the low number of citations of the articles made by only Brazilian authors is because they were published in the Portuguese language and therefore have less international impact.

The main variables of the articles published on grafting from the most prolific countries from 1979 to 2018 are shown in Table 5. China is in first place, with a total of 255 articles and 2723 citations, which is an average of 10.68 citations for each article on grafting. After Brazil and India, this is the third lowest average of citations per article from the table. It is possible that the reason the average number of citations is low is that in these three cases, more than $80 \%$ of articles were published in the last decade, 2009-18. In the case of China, this percentage reaches $89.4 \%$. The United States is placed second in the number of articles, with a total of 231, and it presents the highest total number of citations, 7520 , which is more than 


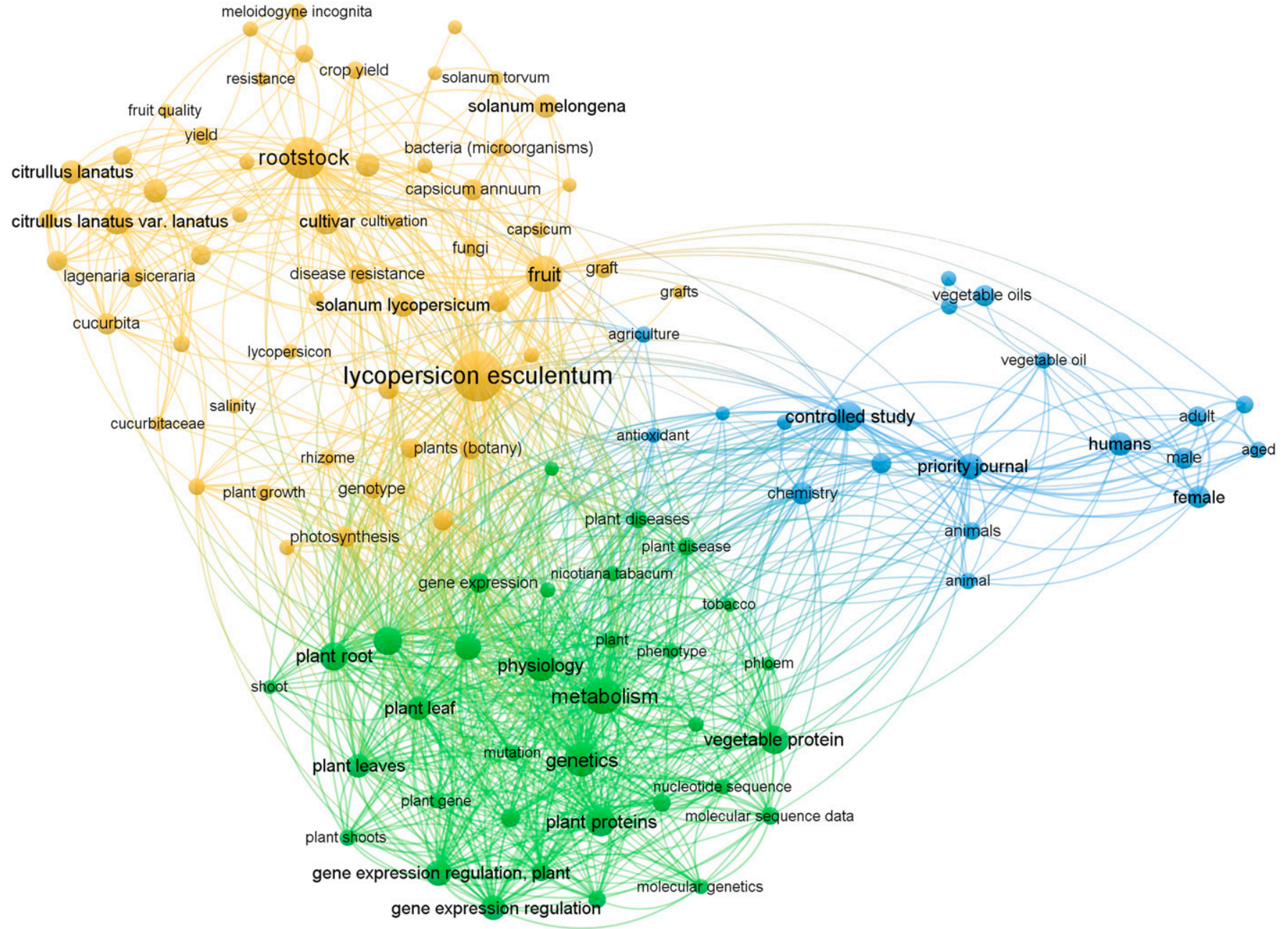

Fig. 5. Keywords network based on co-occurrence from 1979 to 2018.

twice the number of citations of the second country, Spain, with 3478 citations. The country with the highest number of citations per article is Germany, with 39.21. The United States has the highest $\mathrm{H}$ index, with 45 , followed by Spain, with 33, which provides evidence of the interest of American and Spanish publications on grafting. Nevertheless, although United States led the most prolific countries ranking on grafting articles during periods 1989-98 and 1999-2008, in the past decade it has been surpassed by the research power of China. Behind these three countries, Italy and Japan are placed with 94 and 93 articles respectively, although only Italy has improved its position in the past 10 years, from the fifth position in the 19992008 decade to fourth position in the last period, 2009-18. These five countries, China, United States, Spain, Italy, and Japan, are the main research drivers in grafting research, having published $57 \%$ of the total number of articles worldwide.

The other five countries-India, Brazil, Turkey, United Kingdom, and Germanyhave a lower number of articles. Within this group, the United Kingdom led the ranking during the period 1979-88, with seven articles, and during the period 2009-18, it occupied the 11th position. Despite the loss of research drive, United Kingdom is the country with the highest number of citations, 2146, and the highest $\mathrm{H}$ index, 24, within these five countries.

Those variables in relation to international collaboration between countries are shown in Table 6 . The countries with the highest percentage of articles with international cooperation are Germany with $74.50 \%$ (35 of the 47 articles are attributed to Germany), followed by the United Kingdom, with $53.3 \%$; Italy, with $38.3 \%$; and Spain, with $34.2 \%$. They are followed by the United States with $33.8 \%$. India is the country with the least percentage of international collaboration, with $12.7 \%$. Note that, except for Italy and the United Kingdom, in all the countries included in the ranking, the number of citations of articles that have been done with international collaboration is higher than the articles done without collaborations.

A network map illustrating the collaborative relationships between the main countries based on coauthorship is shown in Fig. 4. The different colors represent the various clusters formed by the groups of countries, and the size of the circle varies with the number of articles published by each country. Therefore, the bigger the circle of each country, the higher the number of articles published by authors representing those countries.

The map shows six clusters. The first (yellow) includes the United States, India, Israel, South Korea, and Australia, among others. This is the main group with respect to the number of articles because it includes 517 articles, or $37.6 \%$ of the total number of articles on grafting over the past 40 years. The second cluster (red) is led by China with 366 articles, which represents $26.6 \%$ of the total and includes countries such as Japan, Indonesia, and Pakistan. The third group, green, is led by Spain, with 261 articles, or $19 \%$ of the total number of articles, and it shares works with Argentina, Brazil, France, and the Netherlands. The fourth cluster, blue, is led by Italy, and as the third cluster includes 261 articles. The fourth cluster includes Italy, in addition to Cyprus, Germany, Greece, Lebanon, and Turkey. The fifth cluster, gray, is led by the United Kingdom, with 106 articles, $7.7 \%$ of the total and includes Belgium, the Czech Republic, Hungary, Poland, and Slovenia. Finally, the sixth cluster (pink), includes Austria, Canada, Romania, Sweden, and Switzerland, with a total of 65 articles, or $4.7 \%$ of the total number of articles. 
Keywords analysis. The 20 most frequently used keywords in the 1376 articles on grafting published during the period 1979 2018 are shown in Table 7. The entire period is shown as well as the 10 -year subperiods.

If we consider as agronomic terms Grafting + Grafting (Chemical) + Plant Root + Plant Roots, these represented $68.1 \%$ in the 1979 80 decade (first studied decade) and, when the percentages of Tomato + Citrullus lanatus were added, it amounted to $86.7 \%$. In the $2009-18$ decade, that percentage amounted to $78.5 \%$ and $96.4 \%$, respectively.

A network map of the keywords of the research articles on grafting for the period 1979-2018 is shown in Fig. 5. Three main research lines can be distinguished and they are grouped under the terms "Lycopersicon esculentum," "controlled study," and "rootstock." Such lines basically belong to the agronomic development of horticultural grafting. The consolidation of grafted tomato plants is appreciated because of the worldwide significance of this vegetable.

\section{Conclusions}

This work has presented the advantages of grafting for horticultural development worldwide. It focuses on the development of research during the past 40 years and the distribution of the subject area in the main indexed journals in Scopus database. A bibliometric analysis of 1376 articles was carried out, and we identified the subject areas, journals, authors, institutions, and the most prolific countries in publications on horticultural grafting.

The number of scientific articles on "grafting on vegetables" per year increased during the period 1979-2018, mainly in the last decade, when 1004 articles, representing $73 \%$ of the published articles, were published. The subject area of Agricultural and Biological Sciences is the most important with respect to article grouping (51\%), with a distant second position held by Biochemistry, Genetics and Molecular Biology (17\%).

The most productive journal on grafting was Scientia Horticulturae with $6 \%$ of the total number of articles published (81) during the period of study; it had 1445 citations. This journal has the highest $\mathrm{H}$ index for articles published on horticultural grafting (23), which is much lower than the $\mathrm{H}$ index for all the subject areas (84). The journal Plant Physiology has better results in this area with 1613 citations.

The most prolific authors on horticultural grafting are the Italians Giuseppe Colla and Youssef Rouphael, with 20 articles each. The author with the highest number of citations on this subject area is Giuseppe Colla with 1026 and the highest $\mathrm{H}$ index (17). The Italians Colla, Roupahel, and Cardarelli are the authors with the highest number of citations per article, as well as the highest $\mathrm{H}$ index. Within the most prolific group of authors, the Chinese authors Zhilong Bie and Yuang Huang have the lowest number of citations.
The most prolific institutions in this subject area are the Agricultural Research Organization of Israel with 34 articles and 987 citations. Within the top 10 ranking of institutions, Spain has a higher presence with three institutions. By countries and number of articles published for the subject area, we find China with 255 articles, the United States with 231, and Spain with 117. The countries with a higher percentage of works with international collaboration were Germany and the United Kingdom.

\section{Literature Cited}

Alexandre, B.M., A. Marreiros, and J.S. Dias. 1997. Influencia do tipo de enxertia e do porta-enxerto, na produtividade, precocidade e qualidade do melâo Galia em estufa, no Algarve. II Congresso Iberoamericano-III Congreso Ibérico em Ciencias Hortícolas. Vilamoura Algarve. Actas de Horticultura, p. $147-152$.

Andrews, K.P. and C.S. Marquez. 1993. Graft incompatibility. In: Jules Janick (ed). Horticultural Reviews 15. Wiley, Hoboken, NJ.

Aznar-Sánchez, J.A., L.J. Belmonte-Ureña, J.F. Velasco-Muñoz, and F. Manzano-Agugliaro. 2018. Economic analysis of sustainable water use: A review of worldwide research. J. Clean. Prod. 198:1120-1132.

Bello, A., J.A. López-Pérez, L. Díaz-Viruliche, and J. Tello. 2001. Alternatives to methyl bromide for soil fumigation in Spain. In: Global report on validated alternatives to the use of methyl bromide for soil fumigation. Food and Agriculture Organization and United Nations Environmental Programme, Rome, Italy.

Choi, K.S., H. Om, D.Y. Parks, S.S. Lee, and C.H. Lee. 1991. The interspecific hybrid Weonkio 601 as a rootstock for cucurbits. Res. Rep. of the office of Rural Development, Hort. and Sericiculture. 1980. Suwon 22. (Cited by Miguel et al., in Horticulture 1991;66:34-40). 31 Jan. 2019. <https://www.mapa.gob.es/ ministerio/pags/biblioteca/revistas/pdf_Hort/ Hort_1991_66_completa.pdf>.

Cobo, M.J., A.G. López-Herrera, E. HerreraViedma, and F. Herrera. 2011. Science mapping software tools: Review, analysis, and cooperative study among tools. J. Amer. Soc. Inf. Sci. Technol. 62:1382-1402.

Cohen, R., S. Pivonia, Y. Burger, M. Edelstein, A. Gamliel, and J. Katan. 2000. Toward integrated management of Monosporascus wilt of melons in Israel. Plant Dis. 84:496-505.

Díaz-Pérez, M., F. Camacho-Ferre, F. DiánezMartínez, M. De Cara-García, and J.C. TelloMarquina. 2009. Evaluation of alternatives to methyl bromide in melon crops in guatemala. Microb. Ecol. 57:379-383.

Donohue, J.C. 1972. A bibliometric analysis of certain information science literature. J. Amer. Soc. Inf. Sci. 23:313-317.

Gamayo, J.D. and A. Aguilar. 1998. Ensayo sobre la influencia del injerto en melón Cantalupo bajo invernadero, p. 143-147. Memoria de Actividades, Fundación Caja Rural de Valencia, Spain.

Gavel, Y. and L. Iselid. 2008. Web of Science and Scopus: A journal title overlap study. Online Inf. Rev. 32(1):8-21.

Hartmann, H.T. and D.E. Kester. 1991. Propagación de plantas, principios y prácticas. CECSA, México City, México.

Hossain, M.S., S.J. Pogue, L. Trenchard, A.P.E Van Oudenhoven, C.L. Washbourne, E.W.
Muiruri, A.M. Tomczyk, M. García-Llorente, R. Hale, V. Hevia, T. Adams, L. Tavallali, S. De Bell, M. Pye, and F. Rsende. 2018. Identifying future research directions for biodiversity, ecosystem services and sustainability: Perspectives from early-career researchers. Intl. J. Sustain. Dev. World Ecol. 25:249-261.

Huitrón, M.V., M. Diaz, F. Diánez, and F. Camacho. 2007a. The effect of various rootstocks on triploid watermelon yield and quality. J. Food Agric. Environ. 5:344-348.

Huitrón, M.V., M. Diaz, F. Diánez, F. Camacho, and A. Valverde. 2007b. Effect of 2,4-D and CPPU on triploid watermelon production and quality. HortScience 42:559-564.

Huitrón-Ramírez, M.V., M. Ricárdez-Salinas, and F. Camacho-Ferre. 2009. Influence of grafted watermelon plant density on yield and quality in soil infested with melon necrotic spot virus. HortScience 44:1838-1841.

Kato, T. and Lou, H. 1989. Effects of rootstock on the yield, mineral nutrition and hormone level in xylem sap in eggplant. J. Jpn. Soc. Hortic. Sci. 58:345-352.

Lee, J. M. 1989. On the cultivation of grafted plants of cucurbitaceous vegetables [in Korean with English summary]. J. Kor. Soc. Hort. Sci. 30:169-179.

Lee, J.M. 1994. Cultivation of grafted vegetables. I. Current status, grafting methods, and benefits. HortScience 29:235-239.

Lee, J.M. and M. Oda. 2003. Grafting of herbaceous vegetables and ornamental crops, 61124. In: J. Janick (ed.). Horticultural Reviews. Vol. 28. John Wiley \& Sons, Inc., New York.

Leydesdorff, L., S. Carley, and I. Rafols. 2013. Global maps of science based on the new Webof-Science categories. Scientometrics 94:589593.

Liao, C.T. and C.H. Lin. 1996. Photosynthetic responses of grafted bitter melon seedlings to flood stress. Environ. Exp. Bot. 36:167-172.

Louvet, J. and J. Peyriere. 1962. Intérêt du greffage du melon sur Benincasacerifera, p. 167-171. XVI Congrès Internat. Hortic. Brussels, Belgium.

Louvet, J. 1974. L'utilisation du greffage en culture marichere, p. 19-24. PHM RevueHort.

Marukawa, S. 1979. Studies on varieties of Cucurbita spp. as rootstock for cucurbitaceous vegetables, with special reference to their grafting compatibility (in Japanese with English summary). Bull Ibaraki. Hort. Exp. Sta. Special issue.

Messiaen, C., D. Blancard, F. Rouxel, and F. Lafon. 1991. Les maladies des plantes maraìchères. 3rd ed. Ed. INRA, Paris, France.

Miguel, A. 1997. Injerto de hortalizas. Serie Divulgació Técnica. Ed. Generalitat Valenciana. España. ISBN: 84-482-1601-6. 88 pp.

Mongeon, P. and A. Paul-Hus. 2016. The journal coverage of Web of Science and Scopus: A comparative analysis. Scientometrics 106:213228.

Ogbuji, R.O. 1981. Root size as a factor in the tolerance of six cucurbits to Meloidogyne javanica infection. E. Afr. Agr. For. J. 43(4):410-412.

Okimura, M., S. Matsuo, K. Arai, and S. Okitsu. 1986. Influences of soil temperature on the growth of fruit vegetable grafted on different rootstocks [in Japanese with English summary]. Bul. Natl. Res. Inst. Veg. Ornam. Plants Tea. C9:43-58

Perea-Moreno, A.J., M.Á. Perea-Moreno, Q. Hernandez-Escobedo, and F. Manzano-Agugliaro. 2017. Towards forest sustainability in Mediterranean countries using biomass as fuel for heating. J. Clean. Prod. 156:624-634. 
Ricárdez-Salinas, M., M.V. Huitrón-Ramírez, J.C. Tello-Marquina, and F. Camacho-Ferre. 2010. Planting density for grafted melon as an alternative to methyl bromide use in Mexico. Scientia Hort. 126:236-241.

Rivero, R., J. Ruiz, and Romero, L. 2003. Role of grafting in horticultural plants under stress conditions. J. Food Agric. Environ. $1: 70-74$.

Robinson, R.W. and D.S. Decker-Walters. Cucurbits. 1997. CAB International, Wallingford, UK.
Suzuki, E. La sandía des Yamato. 1972. Brochure translated into Spanish by $\mathrm{Mr}$ Kimura to Alfredo Miguel Gómez in 1977.

Tachibana, S. 1982. Comparison of root temperature on the growth and mineral nutrition of cucumber cultivars and fig leaf gourd [in Japanese with English summary]. Japan. Soc. Hort. Sci. 1:299-308.

Traka-Mavrona, E., M. Koutsika-Sotiriou, and T. Pritsa. 2000. Response of squash (Cucurbita spp.) as rootstock for melon (Cucumis melo L.). Scientia Hort. 83:353-362.
Trionfetti Nisini, P., G. Colla, E. Granati, O. Temperini, P. Crinò, and F. Saccardo. 2002. Rootstock resistance to fusarium wilt and effect on fruit yield and quality of two muskmelon cultivars. Scientia Hort. 93:281288.

van Eck, N.J. and L. Waltman. 2010. Software survey: VOSviewer, a computer program for bibliometric mapping. Scientometrics. 84:523538.

Vergniaud, P. 1990. Le melon: Vendre et produire. P.H.M Revue Hort. 303:43-51. 